\title{
Cigarette smoking, proteinuria, and renal function in middle-aged Japanese men from an occupational population
}

\author{
Yuka Noborisaka - Masao Ishizaki - Minori Nakata - Yuichi Yamada • \\ Ryumon Honda $\cdot$ Hitoshi Yokoyama $\cdot$ Masaru Miyao $\cdot$ Masaji Tabata
}

Received: 2 March 2011 / Accepted: 30 July 2011/Published online: 24 August 2011

(C) The Japanese Society for Hygiene 2011

\begin{abstract}
Objectives To clarify the renal effects of cigarette smoking in a middle-aged occupational population because the effects have previously been demonstrated mainly in community populations that included many elderly people who are thought to be vulnerable to such effects.

Methods In 990 middle-aged men recruited from a chemical plant, proteinuria was measured by a dipstick method and the glomerular filtration rate was estimated (eGFR) using a formula proposed by the Japanese Society of Nephrology.

Results Proteinuria was found in $4.6 \%$ of the current smokers and $1.5 \%$ of the never-smokers. It was found in $4.8 \%$ of the subjects having a Brinkman index (BI) of 400-599 and $6.3 \%$ of those having a BI of 600 or above. The odds ratio for proteinuria in them was 2.94 (CI: 1.01-8.55) and 3.61
\end{abstract}

Y. Noborisaka $(\varangle) \cdot$ M. Ishizaki · M. Nakata $\cdot$ Y. Yamada Department of Social and Environmental Medicine, Kanazawa Medical University School of Medicine, 1-1 Daigaku, Uchinada, Ishikawa 920-0293, Japan

e-mail: hygiene@kanazawa-med.ac.jp

R. Honda

Kanazawa Medical University School of Nursing,

Uchinada, Ishikawa, Japan

H. Yokoyama

Division of Nephrology, Kanazawa Medical University

School of Medicine, Uchinada, Ishikawa, Japan

\section{Miyao}

Graduation School of Information Science,

Nagoya University, Nagoya, Aichi, Japan

M. Tabata

Ishikawa Health Service Association,

Kanazawa, Ishikawa, Japan
(CI: 1.29-10.1), respectively, adjusting for possible confounders. The mean eGFR was higher in smokers than in nonsmokers throughout middle age up to 64 years. Normal but high eGFR was found in $6.7 \%$ of the current heavy smokers and subnormal eGFR in $5.7 \%$ of the largest cumulative cigarette consumers in contrast to $3.0 \%$ or less of the never-smokers. Proteinuria was found in $13.3 \%$ of the subjects showing subnormal eGFR, specifically in $16.7 \%$ of the smokers and $8.3 \%$ of the nonsmokers.

Conclusions Smoking causes proteinuria in working middle-aged men. Smokers tend to have a high eGFR, but those with subnormal eGFR showed proteinuria most frequently. Whether the high eGFR in smokers will eventually decrease and cause proteinuria remains an important focus for further studies.

Keywords Smoking · Proteinuria · eGFR - General population · Worksite

\section{Introduction}

Chronic cigarette smoking causes deterioration of renal function, which was first demonstrated in patients with kidney diseases, including diabetic nephropathy, hypertensive nephrosclerosis, polycystic kidney, and glomerulonephritis in the last decade of the last century, with subsequent evidence accumulating even in the general population from communities since 2000 and after [1-3]. The typical adverse renal effects of smoking have been demonstrated as a 2 to 3 -fold increase in the development of albuminuria or proteinuria and/or decreased glomerular filtration rate (GFR). Smoking is thus a definite cause of chronic kidney disease (CKD) in the general population. However, it should also be noted that in the previous 
studies in both patient groups and in the general population, the adverse effects on the kidney were suggested to be prominent in elderly smokers aged 60-65 years or older [2, 4, 5].

At present, usually in occupational populations from worksites, most workers are less than 60 years old, and thus would not be expected to be as vulnerable to the renal effects of smoking as community populations that usually include a considerably high proportion of elderly persons. At least partly because of the less marked vulnerability of the occupational population to the renal effects of smoking, smoking-induced renal damage has not been fully demonstrated in definite occupational populations except in our previous study [6], to the best of our knowledge.

On the other hand, it was noticed as early as the 1970s that serum creatinine $(\mathrm{Cr})$ concentrations are lower in smokers than in nonsmokers [7, 8], although the biological implications of this phenomenon have remained undetermined. We proposed in a previous study [9] that low serum $\mathrm{Cr}$ in smokers is a reflection of increased excretion of $\mathrm{Cr}$ based on the findings that low serum $\mathrm{Cr}$ was persistently observed after adjusting for body weight and that $\mathrm{Cr}$ clearance estimated using the formula proposed by Cockcroft and Gault [10] was significantly higher in smokers than in nonsmokers. If this hypothesis is correct, since $\mathrm{Cr}$ clearance reflects the GFR, it can be said that cigarette smoking causes an elevation of GFR even though it eventually causes renal damage.

Criticism has been raised in applying the formulae estimating GFR derived from Western populations, such as the Cockcroft and Gault (CG) equation [10] and the Modification of Diet in Renal Disease (MDRD) Study equation [11], to Japanese who have a considerably different body composition and dietary habits from those of Westerners. Very recently, in order to address the criticism, a new formula for estimating GFR in Japanese adults has been proposed by the Japanese Society of Nephrology (JSN) [12].

The purpose of the present study is to determine the relationship between the amount of cigarette consumption and the prevalence of proteinuria in middle-aged men recruited from a chemical plant, which will help to clarify the features of smoking-induced renal damage as an emerging healthcare issue in occupational populations. Another aim of the present study is to estimate GFR (eGFR) in Japanese smokers using the new JSN formula, and to examine its associations with cigarette consumption and the appearance of proteinuria.

\section{Subjects and methods}

The subjects in the present study were recruited from workers of a chemical plant that has a total of 1,928 male and 328 female employees aged 18-64 years. Around 70\% of both the male and female workers in this plant are manual laborers, mostly machine operators; $20 \%$ of the male workers are engineers for the research and developments of products, and the remaining male and female workers are clerical staff. Some of the laborers and engineers regularly handle some renal toxic chemicals, such as lead, cadmium, and various kinds of organic solvents, and they have undergone specific examinations for detecting any adverse health effects due to exposure to such chemicals according to the legal regulations issued by the Ministry of Health, Labour and Welfare, Japan.

The study subjects comprised 990 generally healthy middle-aged men who were selected from all the 1,077 male workers at the ages of 30,35 , and 40 years or older in this plant, who were required to undergo blood tests including determination of serum $\mathrm{Cr}$ concentrations in the annual general health check-up conducted in the autumn of 2009. Female workers were excluded from the subjects because of the small number of smokers. Written informed consent was obtained from all the 1,077 candidates for the anonymous use of their health check-up data in this study. The aims and methods of this study were reviewed and approved by the ethics committee of Kanazawa Medical University.

In the health check-up, blood pressure (BP) was measured by experienced nurses using an automatic manometer (HEM-907, Omron Healthcare Co., Kyoto) with the subjects in a sitting position after resting on a chair for $5 \mathrm{~min}$ or longer. Candidates who showed a BP of 140/90 mmHg or above or those who had been treated for hypertension were defined as having hypertension (hBP). However, 17 candidates who showed a BP of $180 / 110 \mathrm{mmHg}$ or higher in the health check-up were excluded from the subjects to avoid the effects of hypertensive renal damage on the study results. Actually, three of the 17 severe hypertensive workers showed proteinuria in the urinalysis.

Freshly voided urine samples were measured for glucose and protein concentrations semi-quantitatively with a urine test strip (Aution Sticks-4EA, Arkray Inc., Kyoto) and an exclusive automatic reader (Aution Mini AM-4290, Arkray Inc., Kyoto). The workers who showed positive reactions of glucose $1+$ or more $(100 \mathrm{mg} / \mathrm{dl}$ or more) and of protein +1 or more $(30 \mathrm{mg} / \mathrm{dl}$ or more) were defined as the subjects having glucosuria (UG) and proteinuria (UP), respectively.

Overnight fasting venous blood samples were collected in the morning of the health check-up. Serum samples were separated soon after the blood collection and kept frozen at $-40^{\circ} \mathrm{C}$ until the analyses. Serum biochemical analyses were conducted for the activities of hepatic enzymes, the concentrations of lipids such as total cholesterol (Tchol), LDL-cholesterol (LDLc), HDL-cholesterol (HDLc) and 
triglycerides (TG), and those of uric acid, blood urea nitrogen, and $\mathrm{Cr}$ using an automatic analyzer TBA200FR (Toshiba Medical Systems Co., Otawara, Japan). In the $\mathrm{Cr}$ measurement, an enzyme assay kit distributed by Eiken Chemical Co., Tokyo was used. Fasting blood glucose (FBG) was also measured using the analyzer TBA200FR by a hexokinase/glucose-6-phosphate dehydrogenase method, and hemoglobin A1c (HbA1c) was measured by an enzyme assay using an automatic analyzer DM-JACK II distributed by Kyowa Medical Co., Shizuoka, Japan.

Glomerular filtration rate of the subjects was estimated based on the serum $\mathrm{Cr}$ concentration using the formula proposed by JSN as follows:

$$
\begin{aligned}
\operatorname{eGFR}\left(\mathrm{ml} / \mathrm{min} / 1.73 \mathrm{~m}^{2}\right)= & 194 \times \operatorname{Serum} \mathrm{Cr}^{-1.094} \\
& \times \operatorname{Age}(\text { year })^{-0.287}
\end{aligned}
$$

According to the classifications of chronic kidney disease (CKD) recommended by KDIGO (Kidney Disease: Improving Global Outcomes) [13], eGFR in the subjects was defined as "normal" if it was $90 \mathrm{ml} / \mathrm{min} /$ $1.73 \mathrm{~m}^{2}$ or above, but arbitrarily defined as "normal high" if it exceeded $110 \mathrm{ml} / \mathrm{min} / 1.73 \mathrm{~m}^{2}$. Furthermore, eGFR was defined as "normal low" if it ranged from 60 to $89.9 \mathrm{ml} / \mathrm{min} / 1.73 \mathrm{~m}^{2}$, and "subnormal" if $30-59.9 \mathrm{ml} / \mathrm{min} /$ $1.73 \mathrm{~m}^{2}$, corresponding to stage III CKD. None of the present subjects showed a "depressed" eGFR of less than $30 \mathrm{ml} / \mathrm{min} / 1.73 \mathrm{~m}^{2}$ corresponding to stage IV or V CKD.

The subjects who showed Tchol of $220 \mathrm{mg} / \mathrm{dl}$ or LDLc of $140 \mathrm{mg} / \mathrm{dl}$ or above were defined as having hypercholesterolemia (hChol). Those who showed HDLc less than $40 \mathrm{mg} / \mathrm{dl}$ and those with TG of $150 \mathrm{mg} / \mathrm{dl}$ or above were defined as having low HDLc (lHDLc) and high TG (hTG), respectively. Those who showed FBG of $110 \mathrm{mg} / \mathrm{dl}$ or above or HbA1c of $5.9 \%$ or above were defined as having hyperglycemia (hBG).

The structured way of collecting data of cigarette and alcohol consumption was mentioned in our previous study [6], in which age at starting or quitting smoking was pinpointed as exactly as possible by well-trained nurses referring to the dates of the subjects' big life events, such as school graduation, employment, marriage, birth of a child, and admission to a hospital. Current smoking status was classified into never-smokers, ex-smokers, moderate smokers consuming up to 1 pack (20 cigarettes) per day, and heavy smokers consuming more. Based on the Brinkman Index, i.e., the number of cigarettes (pieces) consumed per day multiplied by the duration (years) of smoking, the cumulative cigarette consumption was classified as BI of 0 (corresponding to never-smoker), 1-399, 400-599, and 600 or above. Usual alcohol consumption was classified into three groups: nondrinkers, moderate drinkers consuming up to 2 drinks (60 $\mathrm{ml}$ of ethanol) per day, and heavy drinkers consuming more. Data regarding the cumulative consumption of alcohol were not collected because of the inaccuracy of the data as mentioned in the previous study [6].

In addition to the 17 men who showed BP of $180 / 110 \mathrm{mmHg}$ or higher as mentioned above, seven were further excluded from the subjects because of the presence of kidney disease, including two who were receiving hemodialysis and for whom urinalyses were not available. Thirteen men who were being treated for diabetes mellitus or showed fasting blood glucose (FBG) of $126 \mathrm{mg} / \mathrm{dl}$ or above or HbA1c of $6.5 \%$ or above in the health check-up were also excluded to avoid the effects of diabetic nephropathy on the study results. Furthermore, 19 slender workers with a body mass index (BMI) lower than $18 \mathrm{~kg} /$ $\mathrm{m}^{2}$ and 31 obese workers who showed BMI of $30 \mathrm{~kg} / \mathrm{m}^{2}$ or above were excluded from the subjects because the estimation of GFR using the new JSN formula has not been validated at the extremes of weight [12].

Finally, 990 male workers aged 30-64 years and whose BMI ranged from 18 to 29.9 were selected as the subjects of generally healthy men. The subjects comprised 87 clerical workers, 163 engineers, and 740 laborers. Among the engineers and laborers, 65 subjects with exposure to lead, 23 to cadmium, and 216 to organic solvents were selected to undergo special health examinations to detect possible adverse health effects due to exposure to those chemicals at the same time as the general health check-up. The jobs of clerical worker, engineer, and laborer were labeled 1-3 grades for sedentariness, and the workers who were to undergo specific examinations for the chemicals were labeled $(+)$ for each chemical.

All the statistical analyses were performed using a program package of IBM SPSS ver. 19 (IBM Japan Inc., Tokyo). After confirming the normal distribution of the continuous variables of age, BMI, systolic and diastolic blood pressure, serum $\mathrm{Cr}$ and eGFR, the differences in the means of the variables between smokers and nonsmokers were tested by $t$ test, the means in the four current and accumulated cigarette consumption levels were tested by one-way analyses of variance (ANOVA), and the means of eGFR in the seven age groups of 30 year olds, 35, 40-44, and each 5 years up to 60-64 with/without cigarette consumption were tested by two-way ANOVA.

The differences in the prevalence of proteinuria and those of "normal high" or "subnormal" eGFR among the different levels of current and accumulated cigarette consumption were tested by $\chi^{2}$-tests, and those associations of cigarette consumption with proteinuria and "subnormal" eGFR were further tested by multiple logistic regression analyses adjusting for possible confounders of major cardiovascular risk factors and those of job sedentariness and possible exposure to renal toxic chemicals. In addition, the association of proteinuria with cumulative cigarette 
Table 1 Prevalence of proteinuria (\%) according to the current and accumulated cigarette consumption

\begin{tabular}{lcclcc}
\hline Current consumption & $n$ & $\begin{array}{l}\text { Prevalence } \\
\text { of proteinuria }\end{array}$ & $\begin{array}{l}\text { Accumulated } \\
\text { consumption (BI) }\end{array}$ & $n$ & Prevalence of proteinuria $^{\mathrm{b}}$ \\
\hline Never-smoker & 396 & $6(1.5)$ & 0 & 396 & $6(1.5)$ \\
Ex-smoker & 115 & $4(3.5)$ & $1-399$ & 232 & $6(2.6)$ \\
Moderate smoker & 404 & $18(4.5)$ & $400-599$ & 186 & $9(4.8)$ \\
Heavy smoker & 75 & $4(5.3)$ & $\geqq 600$ & 176 & $11(6.3)$ \\
\hline
\end{tabular}

BI Brinkman index

${ }^{a}$ Differences in the prevalence of proteinuria are borderline significant in the four current consumption levels $\left(\chi^{2}=6.75, d f=3, p=0.080\right)$

${ }^{\mathrm{b}}$ Differences in the prevalence of proteinuria are significant in the four accumulated consumption levels $\left(\chi^{2}=10.70, d f=3, p=0.013\right)$

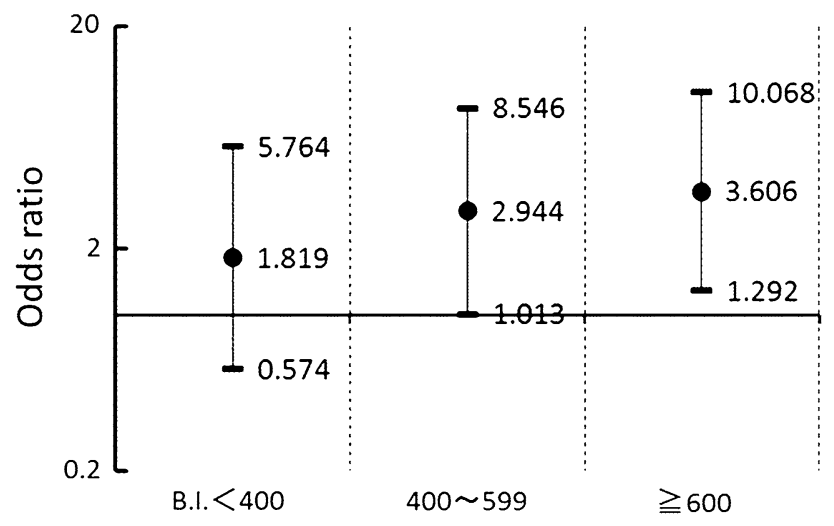

Fig. 1 Odds ratios for the appearance of proteinuria by cumulative cigarette consumption levels in comparison with never-smokers

consumption levels adjusted for eGFR and that with eGFR levels adjusted for cumulative cigarette consumption were evaluated by Mantel-Haenszel analyses.

\section{Results}

The subjects consisted of 66 men aged 30 years, 100 aged 35 years, 284 aged 40-44 years, 204 aged 45-49 years, 137 aged 50-54 years, 153 aged 55-59, and 46 aged 60-64 years, and thus were 990 mostly middle-aged men. The number of subjects who smoked currently was 479 $(48.4 \%)$. Of the 511 who did not smoke, 115 (11.5\%) were ex-smokers and $396(40.0 \%)$ had never smoked. Proteinuria was found in $32(3.2 \%)$ of the total subjects, and in four $(2.4 \%)$ of 166 aged 30 and 35 years, nine (3.2\%) of 284 aged 40-44 years, nine (2.6\%) of 341 aged 45-54 years, and in ten (5.0\%) of 199 aged 55-64 years. The prevalence of proteinuria in the four age groups was not statistically different $\left(\chi^{2}=2.79, d f=3, p=0.425\right)$.

Table 1 shows the prevalence of proteinuria according to the four levels of current and accumulated consumption of cigarettes. Proteinuria was found in six $(1.5 \%)$ of the 396 never-smokers, a lower rate as compared to four $(3.5 \%)$ of the 115 ex-smokers, $18(4.5 \%)$ of the 404 moderate smokers and four (5.3\%) of the 75 heavy smokers. The differences in the prevalence of proteinuria among the four current consumption levels, however, remained at a borderline significance. On the other hand, the prevalence of proteinuria was increased in a dosedependent manner with increases in the cumulative number of cigarettes consumed, namely in 6/232 those with BI of $1-399$ (2.6\%), 9/186 those with BI of 400-599 (4.8\%), and $11 / 176$ those with BI of 600 or above $(6.3 \%)$. These differences were statistically significant.

Multiple logistic regression analysis was performed on the association of the accumulated cigarette consumption with proteinuria adjusting for the possible confounders of major cardiovascular risk factors, such as age, BMI, hBP, UG, hBG, hChol, lHDLc, hTG, and alcohol consumption. hBG and hTG were identified as determinants of proteinuria as well as the cumulative cigarette consumption. Age, $\mathrm{BMI}$, and hBP were not identified in this analysis. The odds ratio (OR) for the appearance of proteinuria was 2.44 and the $95 \%$ confidence interval (CI) ranged from 0.99 to 5.99 when the subjects had hBG, and 2.57 and CI of 1.25-5.37, respectively, when the subjects had hTG. As illustrated in Fig. 1, the subjects with BI of 1-399 showed an OR of 1.82 and the CI ranged from 0.57 to 5.76 , those with BI of 400-599 showed OR of 2.94 and CI of 1.01-8.55, and those of 600 or above showed OR of 3.61 and CI of $1.29-10.1$, in comparison to the never-smokers.

We further analyzed the possible effects of sedentary job and exposure to toxic chemicals in the subjects on the prevalence of proteinuria by a multiple logistic regression analysis using the labels of sedentariness and of possible chemical exposure as the independent variables together with those shown to be related to the prevalence of proteinuria in the analyses mentioned above, such as BI levels, hBG, and hTG. The results, however, did not show significant associations of those labels of job sedentariness and possible chemical exposure with the prevalence of proteinuria.

As shown in Table 2, current smokers showed significantly lower means of BMI, systolic, and diastolic blood pressure, and serum $\mathrm{Cr}$ concentration in comparison to 
Table 2 Means and standard deviations (SDs) of age, body mass index (BMI), blood pressure (BP), serum creatinine (Cr) concentration, and estimated glomerular filtration rate (eGFR) in smokers and nonsmokers

\begin{tabular}{lccr}
\hline Variables & $\begin{array}{l}\text { Smoker }(n=479) \\
\text { mean } \pm \mathrm{SD}\end{array}$ & $\begin{array}{l}\text { Nonsmoker }(n=511) \\
\text { mean } \pm \mathrm{SD}\end{array}$ & $\begin{array}{l}\text { Result } \\
\text { of } t \text { test } p\end{array}$ \\
\hline Age (years old) & $46.0 \pm 8.2$ & $46.3 \pm 8.7$ & 0.633 \\
BMI & $23.2 \pm 2.4$ & $23.6 \pm 2.5$ & 0.032 \\
Systolic BP (mmHg) & $129.0 \pm 16.3$ & $133.7 \pm 16.1$ & $<0.001$ \\
Diastolic BP (mmHg) & $78.5 \pm 11.6$ & $80.6 \pm 10.7$ & 0.002 \\
Serum Cr concentration $(\mathrm{mg} / \mathrm{dl})$ & $0.80 \pm 0.11$ & $0.82 \pm 0.11$ & $<0.001$ \\
eGFR $\left(\mathrm{ml} / \mathrm{min} / 1.73 \mathrm{~m}^{2}\right)$ & $85.4 \pm 13.8$ & $82.2 \pm 13.5$ & $<0.001$ \\
\hline
\end{tabular}

Table 3 Means and standard errors (SEs) of serum Cr concentration and estimated GFR (eGFR) according to the current cigarette consumption levels adjusting for age and BMI

\begin{tabular}{llllll}
\hline Variables & $\begin{array}{l}\text { Never-smoker }(n=396) \\
\text { mean } \pm \mathrm{SE}\end{array}$ & $\begin{array}{l}\text { Ex-smoker } \\
(n=115) \\
\text { mean } \pm \mathrm{SE}\end{array}$ & $\begin{array}{l}\text { Moderate smoker }^{\mathrm{a}} \\
(n=404) \\
\text { mean } \pm \mathrm{SE}\end{array}$ & $\begin{array}{l}\text { Heavy smoker }^{\mathrm{a}} \\
(n=75) \\
\text { mean } \pm \mathrm{SE}\end{array}$ & $\begin{array}{l}\text { Results of }_{\text {GLM }} \\
\text { analysis } p\end{array}$ \\
\hline Serum Cr $(\mathrm{mg} / \mathrm{dl})$ & $0.82 \pm 0.01$ & $0.83 \pm 0.01$ & $0.80 \pm 0.01$ & $0.80 \pm 0.01$ \\
eGFR $\left(\mathrm{ml} / \mathrm{min} / 1.73 \mathrm{~m}^{2}\right)$ & $82.5 \pm 0.65$ & $81.8 \pm 1.21$ & $85.1 \pm 0.64$ & $85.5 \pm 1.49$ & 0.007 \\
\hline
\end{tabular}

GLM generalized linear model

${ }^{a}$ Moderate smokers consume up to one pack (20 cigarettes) per day, and heavy smokers consume more

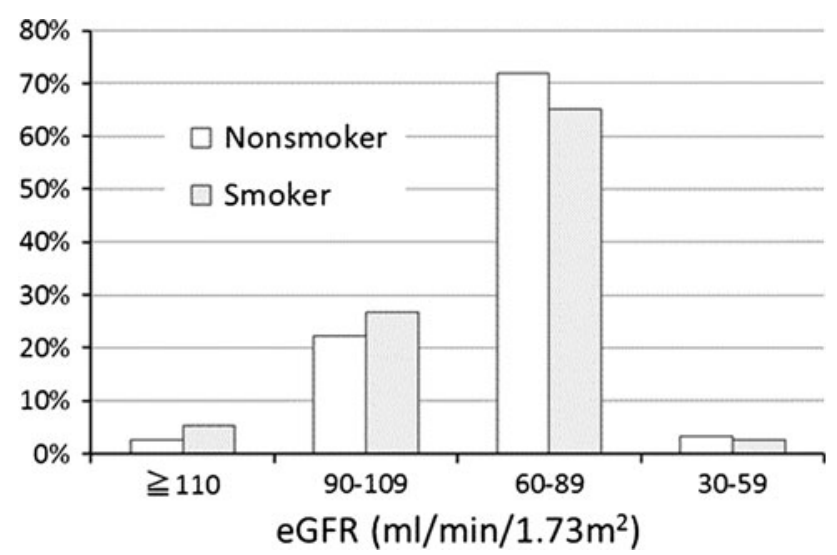

Fig. 2 The distributions of eGFR values in smokers and nonsmokers

nonsmokers. The mean eGFR in smokers was significantly higher than that in nonsmokers. Table 3 shows that the significantly lower serum $\mathrm{Cr}$ and higher eGFR in the current smokers than in the never-smokers and ex-smokers persisted after adjusting for age and BMI, but did not differ between the moderate and heavy smokers. Although not shown in the table, the means of serum $\mathrm{Cr}$ and eGFR were not significantly different between the subjects with different categories of cumulative consumption. Therefore, dose-dependent changes in serum $\mathrm{Cr}$ and eGFR with increases in the amount of cigarette consumption were obscure in the present smokers.

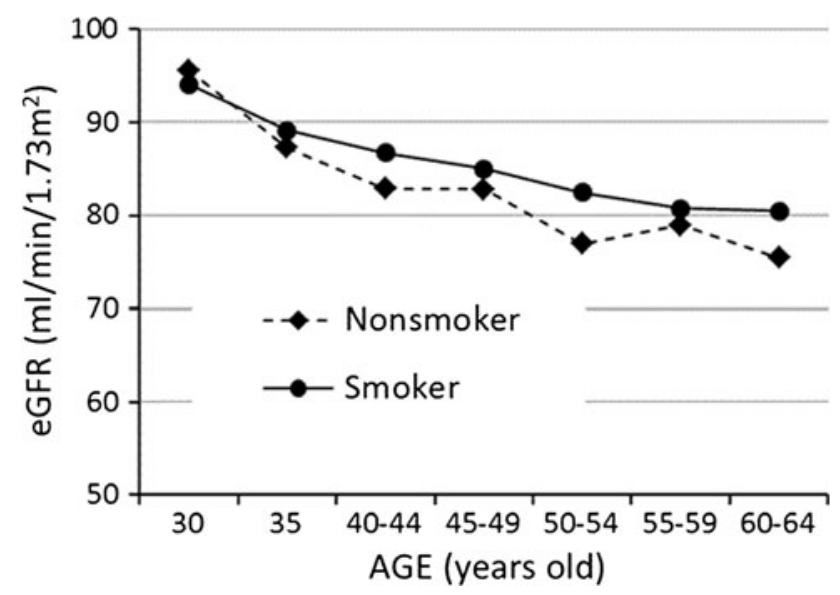

Fig. 3 Age-related changes in the means of eGFR in smokers and nonsmokers

Of the 990 subjects, 281 (28.4\%) showed "normal" eGFR. Among the 281 "normal" subjects, 39 (3.9\%) showed "normal high" eGFR. Apart from those "normal" subjects, 679 (68.6\%) showed "normal low" eGFR and the remaining $30(3.0 \%)$ showed "subnormal" eGFR. Of the 479 current smokers, 154 (32.2\%) showed "normal" eGFR while $127(24.9 \%)$ of the 511 nonsmokers showed the "normal" value (Fig. 2). It is noteworthy that 26 (5.4\%) smokers showed "normal high" eGFR in contrast to only $13(2.5 \%)$ of the nonsmokers. These distributions of eGFR values in smokers and nonsmokers were significantly different $\left(\chi^{2}=10.41, d f=3, p=0.015\right)$. On the other hand, 
Table 4 Prevalence of "normal high" eGFR $\left(\geq 110 \mathrm{ml} / \mathrm{min} / 1.73 \mathrm{~m}^{2}\right)(\%)$ and "subnormal" eGFR $\left(<60 \mathrm{ml} / \mathrm{min} / 1.73 \mathrm{~m}^{2}\right)(\%)$ according to the current and accumulated cigarette consumption levels

\begin{tabular}{|c|c|c|c|c|c|c|c|}
\hline \multirow{2}{*}{$\begin{array}{l}\text { Current } \\
\text { consumption }^{\mathrm{a}}\end{array}$} & \multirow[t]{2}{*}{$n$} & \multicolumn{2}{|l|}{ eGFR } & \multirow{2}{*}{$\begin{array}{l}\text { Accumulated } \\
\text { consumption }(\mathrm{BI})^{\mathrm{b}}\end{array}$} & \multirow[t]{2}{*}{$n$} & \multicolumn{2}{|l|}{ eGFR } \\
\hline & & "Normal high" & "Subnormal" & & & "Normal high" & "Subnormal" \\
\hline Never-smoker & 396 & $11(2.8)$ & $12(3.0)$ & 0 & 396 & $11(2.8)$ & $12(3.0)$ \\
\hline Ex-smoker & 115 & $2(1.7)$ & $5(4.3)$ & $1-399$ & 232 & $12(5.2)$ & $5(2.2)$ \\
\hline Moderate smoker & 404 & $21(5.2)$ & $11(2.7)$ & $400-599$ & 186 & $9(4.8)$ & $3(2.7)$ \\
\hline Heavy smoker & 75 & $5(6.7)$ & $2(2.7)$ & $\geqq 600$ & 176 & $7(4.0)$ & $10(5.7)$ \\
\hline
\end{tabular}

BI Brinkman index

a The prevalence of "normal high" eGFR was highest in the current heavy smokers among the four current cigarette consumption levels, but the difference was not statistically significant $(p=0.109)$

b The prevalence of "subnormal" eGFR was highest in the subjects having the largest BI among the four accumulated cigarette consumption levels, but the difference was not statistically significant $(p=0.107)$

Table 5 Prevalence of proteinuria (\%) according to the accumulated cigarette consumption and eGFR levels

\begin{tabular}{|c|c|c|c|c|}
\hline \multirow{2}{*}{$\begin{array}{l}\text { Accumulated } \\
\text { consumption (BI) }\end{array}$} & \multicolumn{4}{|c|}{ Levels of eGFR $\left(\mathrm{ml} / \mathrm{min} / 1.73 \mathrm{~m}^{2}\right)$} \\
\hline & $\begin{array}{l}\text { "Normal high" } \\
\geq 110\end{array}$ & $\begin{array}{l}\text { "Normal" } \\
90-109.9\end{array}$ & $\begin{array}{l}\text { "Normal low" } \\
60-89.9\end{array}$ & $\begin{array}{l}\text { "Subnormal" } \\
30-59.9\end{array}$ \\
\hline 0 & $0 / 11(0.0)$ & $1 / 97(1.0)$ & $4 / 267(1.4)$ & $1 / 12(8.3)$ \\
\hline $1-399$ & $0 / 12(0.0)$ & $2 / 64(3.1)$ & $3 / 151(2.0)$ & $1 / 5(20.0)$ \\
\hline $400-599$ & $0 / 9(0.0)$ & $3 / 45(6.7)$ & $6 / 129(4.7)$ & $0 / 3(0.0)$ \\
\hline$\geqq 600$ & $0 / 7(0.0)$ & $1 / 36(2.8)$ & $8 / 123(6.5)$ & $2 / 10(20.0)$ \\
\hline
\end{tabular}

Mantel-Haenszel's odds ratio for the appearance of proteinuria was 2.33 (CI: 1.09-4.97) in the subjects having the largest BI of 600 or above in comparison with those having smaller BI of 0-599 adjusting for eGFR levels, and it was 4.45 (CI: 1.43-13.9) in the subjects having the lowest eGFR less than $60 \mathrm{ml} / \mathrm{min} / 1.73 \mathrm{~m}^{2}$ in comparison with those having higher eGFR adjusting for BI levels

BI Brinkman index

"subnormal" eGFR was found in $13(2.7 \%)$ smokers and in $17(3.3 \%)$ nonsmokers, and thus was not conspicuously different between smokers and nonsmokers.

As illustrated in Fig. 3, the means of eGFR decreased with advancing age in both smokers and nonsmokers, and the means were consistently higher in smokers than in nonsmokers in all the age groups up to 60-64 years except for an inverse association in the youngest men aged 30 years. The means of eGFR were significantly different among the seven age groups $(p<0.001)$ as well as between smokers and nonsmokers $(p=0.005)$ by two-way ANOVA.

Table 4 shows that "normal high" eGFR was found in $21(5.2 \%)$ of 404 current moderate smokers and five $(6.7 \%)$ of 75 heavy smokers, being nearly twice more frequent as compared to $11(2.8 \%)$ of 396 never-smokers. On the other hand, "subnormal" eGFR was found most in ten $(5.7 \%)$ of 176 subjects having BI of 600 or above, being also nearly twice as frequent as in $12(3.0 \%)$ of 396 never-smokers. However, the results of $\chi^{2}$ tests on the high prevalence of "normal high" eGFR in the current heavy smokers and "subnormal" eGFR in the largest cumulative cigarette consumers showed $p$ values of 0.109 and 0.107 , respectively, and were not statistically significant.

Multiple logistic regression analyses were performed to reveal the determinants of "subnormal" eGFR in the present subjects. Significant determinants were found to be age $(\mathrm{OR}=1.11$ for each year, $\mathrm{CI}$ : $1.05-1.17)$ and $\mathrm{hBP}$ $(\mathrm{OR}=2.79$, CI: $1.21-6.43)$. Some protective effects of alcohol consumption $(\mathrm{OR}=0.73$ in moderate drinkers and 0.29 in heavy drinkers; $p=0.092$ ) were observed, but cigarette consumption was not identified as a significant determinant of "subnormal" eGFR. None of the labels of sedentariness or possible exposure to renal toxic chemicals showed significant associations with the prevalence of "subnormal" eGFR.

The associations between cumulative cigarette consumption, the levels of eGFR, and proteinuria are summarized in Table 5. Proteinuria was found in none of the subjects having "normal high" eGFR irrespective of cigarette consumption, but was increased with decreases in eGFR levels, namely in seven $(2.9 \%)$ of the subjects with "normal" eGFR, 21 (3.1\%) of those with "normal low" eGFR and four (13.3\%) of those with "subnormal" eGFR. 
In each category of eGFR, proteinuria was more frequent in the subjects having greater cigarette consumption, specifically proteinuria was found in $16.7 \%$ of smokers and $8.3 \%$ of nonsmokers in the subjects showing "subnormal" eGFR. Mantel-Haenszel analyses showed that, adjusting for eGFR levels, OR for the appearance of proteinuria was 2.33 (CI: 1.09-4.97) in the subjects having BI of 600 or above in comparison with those having no or less consumption, BI of 0-599, and that OR was 4.45 (CI: 1.43-13.9) in the subjects with "subnormal" eGFR in comparison with those showing higher eGFR adjusting for the cigarette consumption.

\section{Discussion}

Proteinuria was found in $32(3.2 \%)$ of the 990 mostly middle-aged men recruited from a chemical plant, and the prevalence in the age groups of 30 to 60-64 years in the present subjects was in close accordance with previous findings of proteinuria in $2-5 \%$ of men aged from 30 s to $60 \mathrm{~s}$ in a large-scale general population composed of 574,024 inhabitants (240,594 men and 333,430 women) recruited from various parts of Japan [14]. The present subjects, therefore, can be regarded as representative of the general Japanese population from the viewpoint of prevalence of proteinuria.

As shown in Table 1, proteinuria was increased to $4.5 \%$ of the smokers consuming up to one pack of cigarettes per day and $5.3 \%$ of those consuming more while it was $1.5 \%$ of the never-smokers. A significant dose-dependent association between the number of cigarettes consumed and the appearance of proteinuria was conspicuously observed in the cumulative consumption of cigarettes expressed as BI. Adjusting for possible confounders, subjects having BI of 400-599 and those with BI of 600 or above showed significant OR of 2.94 and 3.61, respectively, for the appearance of proteinuria in comparison to the neversmokers as illustrated in Fig. 1. These findings are consistent with those of our previous study [6] conducted in another occupational population consisting of 10,000 men and 5,000 women who were more strictly selected as healthy workers, in which a significantly high risk of proteinuria was observed in the subjects having BI of 500 or above.

Job sedentariness and possible exposure to renal toxic chemicals of lead, cadmium, and organic solvents in the subjects did not show any significant effects on the prevalence of proteinuria in the multiple logistic regression analyses. During the last 10 years, adverse health effects due to exposure to the chemicals have not been detected in any of the workers in this plant in the specific health examinations, and the periodical measurements of the chemicals in the air of the workshops have shown a fairly well-controlled environmental condition defined as level 1 according to the categories proposed by the Ministry of Health, Labour and Welfare, Japan. It can be surmised, therefore, that any health effects of those chemicals on the plant workers would be minimal even if present. At least for overt proteinuria such as that detected by a dipstick method, no significant effects of exposure to the chemicals were observed. No significant effects of job sedentariness were also detected on the prevalence of proteinuria, and similarly, no significant effects of chemical exposure and job sedentariness on the prevalence of "subnormal", i.e., lowered eGFR were observed in the multivariate analyses.

Although cross-sectional observations like the present study cannot provide evidence of a causal association, previous longitudinal studies conducted in patients with diabetes mellitus [15-17] or hypertension [5, 18] and in the general population [19, 20] have confirmed that smoking induced deterioration of kidney function as manifested by the appearance of proteinuria. Therefore, it can be said that cigarette smoking causes proteinuria even in such a middle-aged population as recruited from worksites, and that the threshold amount of cigarettes consumed before the appearance of proteinuria lies around a BI of 400, corresponding to the consumption of one pack of cigarettes per day for 20 years. This means that moderate smokers as young as 40 years or so may already be at risk of smokinginduced proteinuria.

Being consistent with the present results shown in Table 2, previous reviews of the literature have demonstrated that current smokers tend to have a lower body weight than nonsmokers [21, 22]. Also, a lower blood pressure in current smokers, which persists after adjusting for the lower body weight, has been observed in many epidemiological studies [23, 24]. However, it cannot be said that smokers really have a lower blood pressure than nonsmokers because ambulatory monitoring studies on blood pressure in smokers have often shown a rather higher blood pressure than in nonsmokers [25, 26]. Smoking causes an acute rise of blood pressure. In the epidemiological context, however, blood pressure is often measured at an office after a considerable wait, at least $30 \mathrm{~min}$ or longer, from the last smoking, which may be related to the lower blood pressure noted in smokers in the epidemiological studies [27, 28].

A lower serum $\mathrm{Cr}$ in smokers has also been detected in early studies [7, 8]. The origin of creatinine in serum is muscle cells. The lower serum $\mathrm{Cr}$ in smokers, however, may not be simply explained by the leanness of smokers, i.e., smaller volume of muscle, because the lower serum $\mathrm{Cr}$ persisted after adjusting for BMI as shown in Table 3. Smokers may thus have increased creatinine excretion, which has been demonstrated as a significantly higher $\mathrm{Cr}$ 
clearance calculated from measured $\mathrm{Cr}$ concentrations in the blood and urine of smokers [29, 30]. Further, in accordance with the findings in a French population by Halimi et al. [31], we have observed an elevated $\mathrm{Cr}$ clearance in Japanese smokers, with the $\mathrm{Cr}$ clearance estimated by the CG formula [10] in both studies. The validity of applying the $\mathrm{CG}$ formula to Japanese people is, however, questionable, and a formula for eGFR applicable to Japanese has been required.

The distribution of eGFR values in the present subjects estimated by the new JSN formula applicable to Japanese adults was quite similar to that demonstrated in a largescale general Japanese population mentioned above [14], and the mean eGFR in the current smokers was significantly higher than that in the nonsmokers as shown in Table 3. High eGFR in smokers has also been observed in recent studies conducted in Japan [32] and Korea [33], which used the MDRD formula for the estimation of GFR and in a Japanese study [34] that used the new JSN formula. Although there is a limitation in estimating GFR using any equation composed only of the three variables of sex, age, and serum $\mathrm{Cr}$, it can be said that some smokers tend to have a higher GFR even though cigarette smoking eventually causes renal damage.

The implications of high GFR in smokers, especially its role in the development of renal damage, have remained uncertain. Pinto-Sietsma et al. [30] pointed out that both high and low GFR were observed in smokers. In the present subjects, on one hand, "normal high" eGFR was found in the current smokers nearly twice as frequently as in the nonsmokers, while on the other hand, "subnormal" eGFR was most frequently found in the subjects having large cumulative cigarette consumption, BI of 600 or above, and those two factors, i.e., lowered eGFR and heavy smoking, were both related to the appearance of proteinuria as shown in Table 5. These findings suggest that the high eGFR observed in the current smokers may be temporary, and that it will eventually decrease to a low level with continued smoking and cause proteinuria. However, in the present subjects, the means of eGFR in smokers have remained higher throughout middle age up to 60-64 years, as illustrated in Fig. 3, and a multivariate analysis did not show cigarette consumption to be a significant determinant of "subnormal", i.e., lowered eGFR.

A 10-year follow-up study conducted by Yamagata et al. [19] in a Japanese community population of 41,012 men and 82,752 women aged 40 years or older showed a significant effect of smoking on the decline of eGFR to stage III CKD. The increased risk of such a decline of eGFR in men by smoking was, however, only $10 \%$ during the 10 years. Furthermore, the community population may have included a large proportion of elderly who are thought to be vulnerable to the adverse effects of smoking. Since there have been no studies that detected a decline of GFR due to cigarette smoking in an occupational population, it remains uncertain if smoking is a significant cause of CKD in people at worksites. The change of renal function in middle-aged smokers, especially in those showing a high eGFR, should be investigated by longitudinal observations in occupational populations where eGFR can be monitored annually in each subject. The longitudinal studies will also elucidate if the lowered eGFR observed in the present subjects with the largest cumulative cigarette consumption is a reflection of a "healthy worker effect" or not.

In the present study, proteinuria was found in only $5 \%$ of smokers and no significant effects of smoking were detected in the relation to lowered eGFR. Cigarette smoking may, therefore, exert an adverse renal effect only on limited sensitive subsets of smokers as suggested by Yoon et al. [33]. However, although proteinuria was not detected in smokers with "normal high" eGFR in the present study, more sensitive quantitative measurements of urinary albumin [32] or protein [34] showed positive correlations with elevated eGFR in smokers. In addition, a recent meta-analysis [35] on the results obtained from community populations suggested that not only lowered eGFR of $60 \mathrm{ml} / \mathrm{min} / 1.73 \mathrm{~m}^{2}$ or below but also elevated eGFR of $105 \mathrm{ml} / \mathrm{min} / 1.73 \mathrm{~m}^{2}$ or above, if accompanied by albuminuria or proteinuria, increased the risk for all-cause and cardiovascular mortality. Therefore, the combined effects of elevated eGFR observed in smokers with albuminuria and proteinuria on their health outcomes need to be further investigated.

Microalbuminuria is the earliest manifestation of kidney damage in diabetes mellitus [36-38] and hypertension [39, 40]. It has also been found in cigarette smokers [30], and more prominently in smokers with diabetes mellitus [41] or hypertension [42]. It has also been observed in $6-15 \%$ of the general population [43-46], and thus may be twofold or more sensitive in the detection of early kidney damage than ordinary dipstick-measured proteinuria. Considering that microalbuminuria has been proven to constitute a significant risk for cerebro- and cardiovascular diseases (CVD) [47-49], the measurement of microalbuminuria in such health check-ups as conducted in worksites to detect smokers at high risk of CKD and CVD should be examined for its usefulness as well as the limitations in further studies.

Some limitations of the present study were already mentioned, namely, a cross-sectional observation, limited to male workers, using a low-sensitivity dipstick method for detecting proteinuria, evaluating GFR by an equation composed of only three variables of sex, age, and serum $\mathrm{Cr}$. In addition, the possible biases due to exclusion of the subjects showing an extremely high blood pressure, high blood glucose, and extreme body weight should also be 
considered. Patients with hypertension or diabetes mellitus may have nephropathy and be more vulnerable to the renal toxic effects of smoking [41, 42] and tend to show proteinuria more often. Therefore, the exclusion of the patients with possible hypertension and diabetes mellitus from the subjects in the present study may have weakened the relationship between smoking and renal damage, but at least did not exaggerate the relationship.

Further, we need to point out a critical limitation of estimating GFR in smokers using the JSN formula even though it was proposed specifically for use in Japanese adults. The new JSN formula was derived from subjects mostly composed of CKD patients, and thus its validity is especially weak in the higher range of GFR of $90 \mathrm{ml} / \mathrm{min} /$ $1.73 \mathrm{~m}^{2}$ or above [12], such as was often observed in the current smokers. More accurate methods for evaluating GFR in smokers are thus also required in further investigations.

Acknowledgments This work was supported by KAKENHI, a Grant-in-Aid for Scientific Research (C), 2010, from the Japan Society for the Promotion of Science (JSPS).

\section{References}

1. Orth SR, Hallan SI. Smoking: a risk factor for progression of chronic kidney disease and for cardiovascular morbidity and mortality in renal patients - absence of evidence or evidence of absence? Clin J Am Soc Nephrol. 2008;3:226-36.

2. Orth SR, Ritz E. The renal risks of smoking: an update. Curr Opin Nephrol Hypertens. 2002;11:483-8.

3. Orth SR, Ritz E, Schrier RW. The renal risks of smoking. Kidney Int. 1997;51:1669-77.

4. Bleyer AJ, Shemanski LR, Burke GL, Hansen KJ, Appel RG. Tobacco, hypertension, and vascular disease: risk factors for renal functional decline in an older population. Kidney Int. 2000;57: 2072-9.

5. Regalado M, Yang S, Wesson DE. Cigarette smoking is associated with augmented progression of renal insufficiency in severe essential hypertension. Am J Kidney Dis. 2000;35:687-94.

6. Yamada Y, Noborisaka Y, Ishizaki M, Honda R, Tsuritani I, Yamada S. Association between cigarette consumption and proteinuria in healthy Japanese men and women from an occupational population. J Occup Health. 2004;46:365-73.

7. Dales LG, Friedman GD, Siegelaub AB, Seltzer CC. Cigarette smoking and serum chemistry tests. J Chronic Dis. 1974;27: 293-307.

8. Savdie E, Grosslight GM, Adena MA. Relation of alcohol and cigarette consumption to blood pressure and serum creatinine levels. J Chronic Dis. 1984;37:617-23.

9. Noborisaka Y, Honda R, Ishizaki M, Nakata M, Yamada Y. Alcohol and cigarette consumption, renal function and blood pressure in middle-aged healthy men. J Hum Hypertens. 2007;21:966-8.

10. Cockcroft DW, Gault MH. Prediction of creatinine clearance from serum creatinine. Nephron. 1976;16:31-41.

11. Levey AS, Bosch JP, Lewis JB, Greene T, Rogers N, Roth D. A more accurate method to estimate glomerular filtration rate from serum creatinine: a new prediction equation. Modification of Diet in Renal Disease Study Group. Ann Intern Med. 1999;130: 461-70.

12. Matsuo S, Imai E, Horio M, Yasuda Y, Tomita K, Nitta K, et al. Revised equations for estimated GFR from serum creatinine in Japan. Am J Kidney Dis. 2009;53:982-92.

13. Levey AS, Eckardt KU, Tsukamoto Y, Levin A, Coresh J, Rossert J, et al. Definition and classification of chronic kidney disease: a position statement from Kidney Disease: Improving Global Outcomes (KDIGO). Kidney Int. 2005;67:2089-100.

14. Imai E, Horio $M$, Watanabe $T$, Iseki $K$, Yamagata $K$, Hara $S$, et al. Prevalence of chronic kidney disease in the Japanese general population. Clin Exp Nephrol. 2009;13:621-30.

15. Chase HP, Garg SK, Marshall G, Berg CL, Harris S, Jackson WE, et al. Cigarette smoking increases the risk of albuminuria among subjects with type I diabetes. JAMA. 1991;265:614-7.

16. Chuahirun T, Wesson DE. Cigarette smoking predicts faster progression of type 2 established diabetic nephropathy despite ACE inhibition. Am J Kidney Dis. 2002;39:376-82.

17. Klein R, Klein BE, Moss SE, Cruickshanks KJ. Ten-year incidence of gross proteinuria in people with diabetes. Diabetes. 1995;44:916-23.

18. Warmoth L, Regalado MM, Simoni J, Harrist RB, Wesson DE. Cigarette smoking enhances increased urine albumin excretion as a risk factor for glomerular filtration rate decline in primary hypertension. Am J Med Sci. 2005;330:111-9.

19. Yamagata K, Ishida K, Sairenchi T, Takahashi H, Ohba S, Shiigai $\mathrm{T}$, et al. Risk factors for chronic kidney disease in a communitybased population: a 10-year follow-up study. Kidney Int. 2007;71: $159-66$.

20. O’Seaghdha CM, Hwang SJ, Upadhyay A, Meigs JB, Fox CS. Predictors of incident albuminuria in the Framingham Offspring cohort. Am J Kidney Dis. 2010;56:852-60.

21. Klesges RC, Meyers AW, Klesges LM, La Vasque ME. Smoking, body weight, and their effects on smoking behavior: a comprehensive review of the literature. Psychol Bull. 1989;106:204-30.

22. Molarius A, Seidell JC, Kuulasmaa K, Dobson AJ, Sans S. Smoking and relative body weight: an international perspective from the WHO MONICA Project. J Epidemiol Community Health. 1997;51:252-60.

23. Friedman GD, Klatsky AL, Siegelaub AB. Alcohol, tobacco, and hypertension. Hypertension. 1982;4:III143-50.

24. Green MS, Jucha E, Luz Y. Blood pressure in smokers and nonsmokers: epidemiologic findings. Am Heart J. 1986;111:932-40.

25. Mann SJ, James GD, Wang RS, Pickering TG. Elevation of ambulatory systolic blood pressure in hypertensive smokers. A case-control study. JAMA. 1991;265:2226-8.

26. Pickering TG, Schwartz JE, James GD. Ambulatory blood pressure monitoring for evaluating the relationships between lifestyle, hypertension and cardiovascular risk. Clin Exp Pharmacol Physiol. 1995;22:226-31.

27. Groppelli A, Giorgi DM, Omboni S, Parati G, Mancia G. Persistent blood pressure increase induced by heavy smoking. J Hypertens. 1992;10:495-9.

28. Minami J, Ishimitsu T, Matsuoka H. Effects of smoking cessation on blood pressure and heart rate variability in habitual smokers. Hypertension. 1999;33:586-90.

29. Goetz FC, Jacobs DR Jr, Chavers B, Roel J, Yelle M, Sprafka JM. Risk factors for kidney damage in the adult population of Wadena, Minnesota. A prospective study. Am J Epidemiol. 1997;145:91-102.

30. Pinto-Sietsma SJ, Mulder J, Janssen WM, Hillege HL, de Zeeuw $\mathrm{D}$, de Jong PE. Smoking is related to albuminuria and abnormal renal function in nondiabetic persons. Ann Intern Med. 2000; 133:585-91.

31. Halimi JM, Giraudeau B, Vol S, Caces E, Nivet H, Lebranchu Y, et al. Effects of current smoking and smoking discontinuation on 
renal function and proteinuria in the general population. Kidney Int. 2000;58:1285-92.

32. Ishizaka N, Ishizaka Y, TodaEi-ichi, Shimomura H, Koike K, Seki G, et al. Association between Cigarette Smoking and Chronic Kidney Disease in Japanese Men. Hypertension Res. 2008;31:485-92.

33. Yoon HJ, Park M, Yoon H, Son KY, Cho B, Kim S. The differential effect of cigarette smoking on glomerular filtration rate and proteinuria in an apparently healthy population. Hypertens Res. 2009;32:214-9.

34. Sauriasari R, Sakano N, Wang DH, Takaki J, Takemoto K, Wang $\mathrm{B}$, et al. C-reactive protein is associated with cigarette smokinginduced hyperfiltration and proteinuria in an apparently healthy population. Hypertens Res. 2010;33:1129-36.

35. Matsushita K, van der Velde M, Astor BC, Woodward M, Levey AS, de Jong PE, et al. Association of estimated glomerular filtration rate and albuminuria with all-cause and cardiovascular mortality in general population cohorts: a collaborative metaanalysis. Lancet. 2010;375:2073-81.

36. Almdal T, Norgaard K, Feldt-Rasmussen B, Deckert T. The predictive value of microalbuminuria in IDDM. A five-year follow-up study. Diabetes Care. 1994;17:120-5.

37. Mogensen CE. Prediction of clinical diabetic nephropathy in IDDM patients. Alternatives to microalbuminuria? Diabetes. 1990;39:761-7.

38. Savage S, Nagel NJ, Estacio RO, Lukken N, Schrier RW. Clinical factors associated with urinary albumin excretion in type II diabetes. Am J Kidney Dis. 1995;25:836-44.

39. Bigazzi R, Bianchi S, Campese VM, Baldari G. Prevalence of microalbuminuria in a large population of patients with mild to moderate essential hypertension. Nephron. 1992;61:94-7.

40. Ljungman S. Microalbuminuria in essential hypertension. Am J Hypertens. 1990;3:956-60.

41. Couper JJ, Staples AJ, Cocciolone R, Nairn J, Badcock N, Henning P. Relationship of smoking and albuminuria in children with insulin-dependent diabetes. Diabet Med. 1994;11:666-9.
42. Mimran A, Ribstein J, DuCailar G, Halimi JM. Albuminuria in normals and essential hypertension. J Diabetes Complicat. 1994;8:150-6.

43. Atkins RC, Polkinghorne KR, Briganti EM, Shaw JE, Zimmet PZ, Chadban SJ. Prevalence of albuminuria in Australia: the AusDiab Kidney Study. Kidney Int Suppl. 2004;S22-4.

44. Gerstein HC, Mann JF, Pogue J, Dinneen SF, Halle JP, Hoogwerf $\mathrm{B}$, et al. Prevalence and determinants of microalbuminuria in high-risk diabetic and nondiabetic patients in the Heart Outcomes Prevention Evaluation Study. The HOPE Study Investigators. Diabetes Care. 2000;23(Suppl 2):B35-9.

45. Hillege HL, Janssen WM, Bak AA, Diercks GF, Grobbee DE, Crijns HJ, et al. Microalbuminuria is common, also in a nondiabetic, nonhypertensive population, and an independent indicator of cardiovascular risk factors and cardiovascular morbidity. J Intern Med. 2001;249:519-26.

46. Konta T, Hao Z, Abiko H, Ishikawa M, Takahashi T, Ikeda A, et al. Prevalence and risk factor analysis of microalbuminuria in Japanese general population: the Takahata study. Kidney Int. 2006;70:751-6.

47. Gerstein HC, Mann JF, Yi Q, Zinman B, Dinneen SF, Hoogwerf $\mathrm{B}$, et al. Albuminuria and risk of cardiovascular events, death, and heart failure in diabetic and nondiabetic individuals. JAMA. 2001;286:421-6.

48. Janssen WM, Hillege H, Pinto-Sietsma SJ, Bak AA, De Zeeuw D, de Jong PE. Low levels of urinary albumin excretion are associated with cardiovascular risk factors in the general population. Clin Chem Lab Med. 2000;38:1107-10.

49. Yuyun MF, Khaw KT, Luben R, Welch A, Bingham S, Day NE, et al. Microalbuminuria independently predicts all-cause and cardiovascular mortality in a British population: The European Prospective Investigation into Cancer in Norfolk (EPIC-Norfolk) population study. Int J Epidemiol. 2004;33:189-98. 